\title{
Facile Synthesis and Polymerization of Ether Substituted Methacrylates
}

\author{
Robert D. Thompson, Thomas B. Barclay, Kumar R. BasU, and Lon J. Mathias* \\ Department of Polymer Science, University of Southern Mississippi, \\ Hattiesburg, MS 39406-0076, U.S.A.
}

(Received May 12, 1994)

\begin{abstract}
New difunctional methacrylate monomers containing $\beta$ heteroatoms have been synthesized from $\alpha$-hydroxymethylacrylate esters or $\alpha$-chloromethylacryloyl chloride. These monomers are more reactive than their alkane counterparts (e.g., ethacrylates), giving polymers with molecular weights comparable to poly(itaconate)s. The simple synthetic approach described allows a wide range of difunctionalized acrylate monomers to be produced. Variations in both ester and ether substituents were explored for ease of synthesis and polymerization.

KEY WORDS Beta-Substituted Methacrylates / Disubstituted Ethylene / Functionalized Acrylates / Water-Soluble Acrylates / Poly(methacrylate)s / Ceiling Temperature / Chain Transfer /
\end{abstract}

Acrylate monomers containing hydrocarbon chains at the $\alpha$-position, such as the ethyl and propyl derivatives (1 and 2, Figure 1), display very poor or no free radical polymerizability at room temperature. ${ }^{1}$ Incorporation of an oxygen atom $\beta$ to the double bond (as in 3) makes monomers which are much more reactive. For example, the methyl ester of the $\alpha$ hydroxymethyl compound polymerizes faster than methyl methacrylate in free radical polymerization, ${ }^{2}$ although ether derivatives give molecular weights only up to $c a$. sixty thousand. ${ }^{3}$ This is comparable to itaconate monomers. Apparently, chain transfer to monomer limits molecular weight for the ethers. ${ }^{4}$

Our group and several others have been exploring the chemistry of 1,1-disubstituted vinyl monomers based on esters of $\alpha$-hydroxymethylacrylate for several years. ${ }^{5}$ Earlier work in this area involved complicated or low yield syntheses of hydroxymethyl compounds and derivatives for use as natural product synthons. $^{6,7}$ We have pursued a simple, clean synthetic approach involving the DABCOcatalyzed insertion of paraformaldehyde at the $\alpha$-position of acrylic esters to produce alkyl $\alpha$-hydroxymethylacrylates ${ }^{8}$ with yields ranging up to approximately $50 \%$ of readily purified monomer. Reaction of the hydroxymethyl group with appropriate reagents gives reactive allyl halides ${ }^{7,9,10}$ capable of highyield conversion to a range of derivatives (Figure 2). The ether's flexibility imparts unique properties to the monomer compared to similar, more rigid ester derivatives; for example, the allyl ether of ethyl $\alpha$-hydroxymethylacrylate undergoes efficient cyclopolymerization to high molecular weight soluble polymers, ${ }^{11}$ in contrast to allyl acrylate and methacrylate.

Characteristics of the polymers obtained from these monomers include the fact that the ether linkage is inherently more stable than an ester linkage and should not be easily

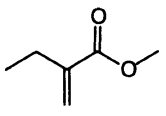

1

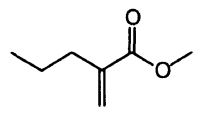

2

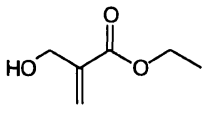

3
Figure 1. Examples of $\alpha$-alkyl acrylates (1 and 2) which give low molecular weight polymers and ethyl $\alpha$-hydroxymethylacrylate (3) which gives high molecular weight polymer. 


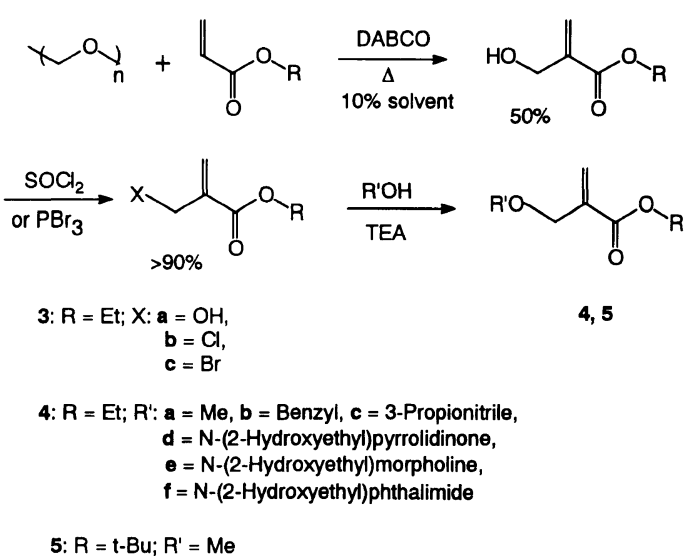

Figure 2. Synthetic scheme for intermediates and ether derivatives.

thermalized or hydrolyzed. In addition, steric inhibition at the carbonyl carbon through the neopentyl effect should also reduce hydrolysis of the ester group in the polymers obtained.

Examples of previous research on $\alpha$-hydroxymethylacrylates include evaluating the kinetics of polymerization of these monomers as 1,1-disubstituted ethylenes. ${ }^{3}$ We have been studying these materials with regard to their utility in liquid crystalline monomers (fluoroalkyl ethers), ${ }^{12}$ cyclopolymers, ${ }^{11}$ and woodpolymer composities via monomer impregnation and polymerization. ${ }^{13}$ Several of the alkyl ethers of ethyl $\alpha$-hydroxymethylacrylate have been reported by others, including the methyl, ethyl, propyl, isopropyl, dodecyl, ${ }^{3}$ and phenyl $^{14}$ ethers. We describe here several new ether derivatives of the ethyl, methyl, and $t$ butyl esters (Figure 2) as examples of the versatility of this overall synthetic approach along with an improved method for obtaining the chloromethyl intermediates.

\section{EXPERIMENTAL}

Methanol, hexane, ethyl ether, and $t$-butyl alcohol were used as received from Fisher Chemical Company. Paraformaldehyde, 1,4diazabicyclo[2.2.2.] octane (DABCO), phosphorous tribromide, 2-pyrrolidinone, $\mathrm{N}$-(2- hydroxyethyl)-2-pyrrolidinone, $\mathrm{N}$-(2-hydroxyethyl)morpholine, $t$-butyl acrylate, and ethyl acrylate were used as received from Aldrich Chemical Company. Triethylamine (TEA, Aldrich) was dried over calcium hydride for $24 \mathrm{~h}$, then distilled into a dry vessel which was sealed and stored. Calcium sulfate (Fisher) was used in air-drying tubes for reaction vessel outlets. 2,2'-Azobis(isobutyronitrile) (AIBN) was recrystallized from methanol before use. Monomer syntheses and purities were monitored by gas chromatography (GC) using a Hewlett-Packard 5890 Gas Chromatograph equipped with an FID detector, 95\% dimethyl/ $5 \%$ diphenyl polysiloxane column, and an HP 3396a Integrator. Monomers and polymers were characterized by ${ }^{13} \mathrm{C}$ NMR spectroscopy with Bruker AC-300 or AC-200 spectrometers. Thermal analyses were done on a Du Pont 9900 analyzer with a 910 or 912 DSC module. Viscosities were determined at $30^{\circ} \mathrm{C}$ using Cannon-Ubbelohde microviscometers and initial polymer concentrations of $c a .0 .5-0.85$ $\mathrm{gdL}^{-1}$ in tetrahydrofuran (THF). Intrinsic viscosity values were obtained by extrapolating least squares fits of both reduced and inherent values to zero concentration. Size-exclusion chromatography (SEC) was carried out with THF solvent, American Polymer Standard Company columns of $500,10^{3}, 10^{4}$, and $10^{6} \AA$ packing, and polystyrene calibration standards ranging from $17.5 \times 10^{3}$ to $3 \times 10^{6}$.

\section{Intermediate Syntheses}

The synthesis of the alkyl $\alpha$-hydroxymethylacrylates (RHMAs) has been previously described ( $\mathrm{R}=$ ethyl and $t$-butyl). ${ }^{5,15} \mathrm{We}$ have improved the yield to approximately $50 \%$ through the use of $t$-butyl alcohol or dimethyl sulfoxide (10 vol\%) as cosolvent. Purity of all monomers was determined by GC before polymerization.

Ethyl $\alpha$-Hydroxymethylacrylate (EHMA, 3a). Ethyl acrylate $(20.0 \mathrm{~mL}, 0.188 \mathrm{~mol})$, paraformaldehyde $(2.82 \mathrm{gm}, 93.9 \mathrm{mmol}), t$-butyl alcohol $(2 \mathrm{~mL}, 10$ vol-\%), 1,4-diazabicyclo- 
[2.2.2.] octane (DABCO) $(1.05 \mathrm{gm}, 9.36 \mathrm{mmol})$, and a teflon-coated stirring magnet were added to a round-bottomed flask. The flask was fitted with a condenser and drying tube and placed into an oil bath preheated to $55^{\circ} \mathrm{C}$. After approximately $8 \mathrm{~h}$ the vessel was removed from the heat and cooled. Ethyl ether $(20 \mathrm{~mL})$ was added to the solution which was then washed three times with $1 \mathrm{wt} \%$ aqueous $\mathrm{HCl}(10 \mathrm{~mL})$. The combined aqueous layers were backextracted with $10 \mathrm{~mL}$ ethyl ether. Organic layers were combined, and solvents and unreacted ethyl acrylate removed using a rotary evaporator. Copper(II) chloride was added as a free-radical inhibitor and the solution vacuum distilled to give $96 \%$ pure ethyl $\alpha$ hydroxymethylacrylate; $50 \%$ overall yield.

Ethyl $\alpha$-Chloromethylacrylate (ECMA, 3b). Ethyl $\alpha$-chloromethylacrylate has been synthesized previously by our group. ${ }^{10,16}$ Pure EHMA (vacuum-distilled from the crude hydroxymethyl monomer synthesis mixture $(77.7 \mathrm{~g}, 0.596 \mathrm{~mol}))$ and a teflon-coated magnetic stir bar were added to a three-neck roundbottom flask in an ice bath. A nitrogen purge was used to remove $\mathrm{HCl}$ gas evolved, which was then trapped in a basic solution. Thionyl chloride $(78.0 \mathrm{~g}, 0.656 \mathrm{~mol})$ was added slowly to the flask. After complete addition, the solution was allowed to warm to room temperature and refluxed for one hour to convert the chlorosulfite intermediate to the primary chloride. Gas chromatographic (GC) analysis of the reaction mixture does not give correct identification of intermediates; therefore, to ensure complete conversion, the reaction was monitored by ${ }^{13} \mathrm{C}$ NMR. Excess thionyl chloride was removed by rotary evaporation. Vacuum distillation gave $99 \%$ pure ethyl $\alpha$-(chloromethyl)acrylate (85\% yield).

Ethyl $\alpha$-Bromomethylacrylate (EBMA). A literature procedure was used for obtaining this intermediate. ${ }^{7,9}$

\section{Ether Monomer Syntheses}

Ethyl $\alpha$-Methoxymethylacrylate (4a). Methyl alcohol $(4.6 \mathrm{~mL}, 113 \mathrm{mmol})$, ethyl $\alpha$-chloromethylacrylate $(8.37 \mathrm{~g}, 56.3 \mathrm{mmol})$, and a teflon-coated magnetic stir bar were placed in a $100 \mathrm{~mL}$ single-neck round-bottom flask. The flask was placed in an ice bath and, with rapid stirring, TEA $(11.6 \mathrm{~mL}, 83.2 \mathrm{mmol})$ was added to the flask slowly via addition funnel. The solution was allowed to come to room temperature and stirred for an additional $8 \mathrm{~h}$. The TEA/HCl salt and excess TEA were extracted by washing three times with $1 \mathrm{wt} \%$ aqueous $\mathrm{HCl}$ solutions ( $10 \mathrm{~mL}$ portions). The aqueous layers were combined and back-extracted with $\mathrm{CH}_{2} \mathrm{Cl}_{2}$ (10 $\mathrm{mL}$ portions). The organic layers were combined and dried with magnesium sulfate. Copper(II) chloride was added as a free-radical inhibitor, and solvent and excess reactants were removed by rotary evaporation. Vacuum distillation gave $98 \%$ pure ethyl $\alpha$-methoxymethylacrylate; $41 \%$ yield.

Ethyl $\alpha$-Benzyloxymethylacrylate (EBzMA, 4b). Benzyl alcohol $(4.15 \mathrm{~mL}, 40.1 \mathrm{mmol})$ and ECMA $(2.88 \mathrm{~g}, 19.4 \mathrm{mmol})$ were added to a $50 \mathrm{~mL}$ round-bottom flask in an ice bath. TEA (3.5 mL, $25.1 \mathrm{mmol})$ was added dropwise with rapid stirring via magnetic stir bar and the reactants heated to $68^{\circ} \mathrm{C}$ and allowed to stir for $21 \mathrm{~h}$. Ethyl ether $(40 \mathrm{~mL})$ was added and the mixture extracted and worked up as above. Vacuum distillation gave $98 \%$ pure ethyl $\alpha$ benzyloxymethylacrylate; $69 \%$ yield.

Ethyl $\alpha$-(3-Propionitrile)oxymethylacrylate (4c). $\alpha$-bromomethylacrylate $(7.25 \mathrm{~g}, \quad 37.6$ mmol) was placed in a $50 \mathrm{~mL}$ round-bottom flask in an ice-bath. 3-Hydroxypropionitrile (3.1 mL, $45.4 \mathrm{mmol})$ and TEA (10.5 mL, 75.3 mmol) were added dropwise to the flask with rapid stirring via magnetic stirring bar. The flask and contents were allowed to warm to room temperature and then placed in a $50^{\circ} \mathrm{C}$ oil bath for $4 \mathrm{~h}$. $20 \mathrm{~mL}$ of $\mathrm{CH}_{2} \mathrm{Cl}_{2}$ was added and the solution washed twice with a $1 \mathrm{vol} \%$ $\mathrm{HCl}$ solution ( $30 \mathrm{~mL}$ portions). Copper(II) chloride was added and the solvent was removed via rotary evaporation. Vacuum distillation gave $94 \%$ pure ethyl $\alpha$-(3-propionitrile) 
oxymethylacrylate; $51 \%$ yield.

$N$-Ethyl Pyrrolidinone Ether (4d). N-(2Hydroxyethyl)-2-pyrrolidinone (11.5 mL, 102 mmol), TEA $(9.5 \mathrm{~mL}, 68.2 \mathrm{mmol})$, and a teflon-coated magnetic stir bar were added to a $100 \mathrm{ml}$ three-neck round-bottom flask in an ice bath. A condenser and nitrogen inlet were fitted to the flask. Ethyl $\alpha$-bromomethylacrylate $(6.63 \mathrm{~g}, 34.3 \mathrm{mmol})$ was added to the flask dropwise through an addition funnel. The solution was allowed to come to room temperature and stirred for $24 \mathrm{~h}$ under positive nitrogen pressure until GC showed complete conversion of the ethyl $\alpha$-bromomethylacrylate. $\mathrm{CH}_{2} \mathrm{Cl}_{2}(10 \mathrm{~mL})$ was added and the solution washed seven times with $1 \mathrm{wt} \%$ aqueous $\mathrm{HCl}$ solution ( $10 \mathrm{~mL}$ portions). The aqueous layers were combined and backextracted with $\mathrm{CH}_{2} \mathrm{Cl}_{2}(10 \mathrm{~mL})$. Solvent was removed by rotary evaporation and the residue vacuum-distilled to give $98 \%$ pure monomer; $51 \%$ yield.

$\mathrm{N}$-Ethyl Morpholine Ether (4e). 4-(2-Hydroxyethyl)morpholine $(14.7 \mathrm{~mL}, 121.4 \mathrm{mmol})$, TEA $(17.0 \mathrm{~mL}, 122 \mathrm{mmol})$, and ethyl $\alpha$ bromomethylacrylate $(7.90 \mathrm{~g}, 40.9 \mathrm{mmol})$ were reacted as for 4d. Work-up and vacuum distillation gave $98 \%$ pure monomer; $67 \%$ yield.

$N$-Ethyl Phthalimide Ether (4f). Ethyl $\alpha$ bromomethylacrylate $(3.59 \mathrm{~g}, 18.6 \mathrm{mmol}), \mathrm{N}$ (2-hydroxyethyl)phthalimide $(7.1 \mathrm{~g}, 56 \mathrm{mmol})$, and TEA $(7.8 \mathrm{~mL}, 56 \mathrm{mmol})$ were added to a round-bottom flask and placed in a $90^{\circ} \mathrm{C}$ oil bath with rapid stirring by magnetic stir bar. After $12 \mathrm{~h}$ the vessel was removed and allowed to cool. Twenty $\mathrm{mL}$ each of ethyl ether and hexane were added to separate liquid from solid. $30 \mathrm{~mL}$ more of $\mathrm{CH}_{2} \mathrm{Cl}_{2}$ were added to dissolve the remaining waxy solid. The solution was washed 3 times with 1 vol\% $\mathrm{HCl}$ solution ( $20 \mathrm{~mL}$ portions) and once with $0.2 \mathrm{wt} \%$ $\mathrm{K}_{2} \mathrm{CO}_{3}$ solution. Solvents were removed by rotary evaporation and the product recrystallized from a methanol and water solution ${ }^{17}$ to give $97 \%$ pure monomer; estimated yield $30 \%$ of a $c a .1: 1$ ratio of ethyl ester to $N$-(2- ethylphthalimido)ester. ${ }^{18}$

$t$-Butyl $\alpha$-Methoxymethylacrylate ( $t$-BMMA, 5). Methyl alcohol $(2.20 \mathrm{~mL}, 54.3 \mathrm{mmol})$ and $t$-butyl $\alpha$-bromomethylacrylate $\left(t\right.$-BBMA $\left.{ }^{19}\right)$ $(4.00 \mathrm{~g}, 18.1 \mathrm{mmol})$ were placed in a $50 \mathrm{~mL}$ round-bottom flask in an ice water bath. TEA ( $7.53 \mathrm{~mL}, 54.0 \mathrm{mmol}$ ) was added to the flask slowly via addition funnel while the solution was stirred rapidly via magnetic stir bar. A viscous gel appeared as the amine was added, due (we believe) to the formation of the $t$ BBMA/TEA salt. The reactants were heated to $65^{\circ} \mathrm{C}$ to dissolve the gel and the solution was allowed to stir for $8 \mathrm{~h}$. Hexane and ether $(10 \mathrm{~mL}$ each) were added and the solution washed three times with $1 \mathrm{wt} \% \mathrm{HCl}$ solution (10 $\mathrm{mL}$ portions). The aqueous layers were combined and back-extracted with $\mathrm{CH}_{2} \mathrm{Cl}_{2}$. Organic layers were combined and dried with magnesium sulfate. Copper(II) chloride was added as a free-radical inhibitor, and solvent and excess reactants were removed by rotary evaporation. Vacuum distillation produced $97 \%$ pure $t$-butyl $\alpha$-methoxymethylacrylate; $49 \%$ yield.

\section{Symmetrical Alkyl $\alpha$-Alkoxymethylacrylates}

\section{Ethers}

$\alpha$-Chloromethylacryloylchloride $(C M A C, 6)$. $t$-Butyl $\alpha$-hydroxymethylacrylate ( $t$-BHMA) $(5 \mathrm{~g}, 31.64 \mathrm{mmol})$ was added to a $50 \mathrm{~mL}$ round-bottom flask. After cooling in an ice bath, excess thionyl chloride $(75.3 \mathrm{~g}, 633 \mathrm{mmol})$ was added dropwise with constant stirring. The temperature was allowed to rise to ambient and stirring continued for $24 \mathrm{~h}$. Most of the excess thionyl chloride was evaporated in a rotary evaporator, and low pressure distillation $^{20}$ of the residue gave $96 \%$ pure CMAC as a clear liquid in $60 \%$ yield.

Methyl $\alpha$-Methoxymethylacrylate (MMMA, 7a). ECMA $(3.37 \mathrm{~g}, 22.7 \mathrm{mmol})$, methanol $(30 \mathrm{~mL})$, and sulfuric acid $(1 \mathrm{~mL})$ were added to a $50 \mathrm{~mL}$ round-bottom flask under nitrogen purge and heated at $70^{\circ} \mathrm{C}$ for $24 \mathrm{~h}$ with stirring via teflon-coated magnetic stirring bar. Meth- 
anol and ethanol were rotary evaporated and $30 \mathrm{~mL}$ more methanol added. The solution was stirred at $70^{\circ} \mathrm{C}$ for $24 \mathrm{~h}$ until GC indicated complete transesterification. The solution was poured into $500 \mathrm{~mL}$ of water at $\mathrm{pH} 11$ and extracted twice with $\mathrm{CH}_{2} \mathrm{Cl}_{2}$ ( $25 \mathrm{~mL}$ portions). The $\mathrm{CH}_{2} \mathrm{Cl}_{2}$ was removed by rotary evaporation. The mixed chloromethyl/methoxymethyl methyl ester (approximately $3: 2$ ratio by ${ }^{13} \mathrm{C}$ NMR) monomer was then added to a roundbottom flask along with methanol $(1 \mathrm{~mL})$ and placed into an ice bath. TEA $(3.3 \mathrm{~mL})$ was added dropwise, the solution warmed to room temperature and then placed into a $75^{\circ} \mathrm{C}$ oil bath. After work-up as for $\mathbf{4 c}$, yield was estimated to be $30-40 \%$.

Ethyl $\alpha$-Ethoxymethylacrylate (7b). Ethanol $(7.74 \mathrm{~g}, 168.4 \mathrm{mmol})$ and TEA $(5.11 \mathrm{~g}, 50.51$ $\mathrm{mmol}$ ) were placed in a $50 \mathrm{~mL}$ round-bottom flask at ambient temperature. ECMA $(5 \mathrm{~g}$, $33.67 \mathrm{mmol}$ ) was added dropwise with rapid stirring and the reaction was continued for $8 \mathrm{~h}$ under reflux. $50 \mathrm{~mL}$ of $\mathrm{CH}_{2} \mathrm{Cl}_{2}$ was added and the solution washed 3 times with water $(25 \mathrm{~mL}$ portions). The organic layer was separated, dried with anhydrous sodium sulfate and evaporated under reduced pressure to remove solvent. Vacuum distillation of the residue gave $99 \%$ pure ethyl $\alpha$-ethoxymethylacrylate as a clear liquid in $70 \%$ yield.

Benzyl $\alpha$-Benzyloxymethylacrylate (7c). Benzyl alcohol (10.27 g, $95 \mathrm{mmol})$, TEA ( $9.61 \mathrm{~g}, 95$ mmol) and dry THF $(25 \mathrm{~mL})$ were placed in a $50 \mathrm{~mL}$ round-bottom flask and cooled to $10^{\circ} \mathrm{C}$. CMAC (6g, $3.2 \mathrm{mmol})$ was added dropwise to the stirring solution. The resulting mixture was stirred for $1 \mathrm{~h}$ before raising the temperature to $50^{\circ} \mathrm{C}$ and stirring for another $12 \mathrm{~h}$. The THF was evaporated and $50 \mathrm{~mL} \mathrm{CH}_{2} \mathrm{Cl}_{2}$ was added to the solution. The solution was washed three times with water $(25 \mathrm{~mL}$ portions), the organic layer separated, dried with anhydrous sodium sulfate and solvent removed under reduced pressure. Vacuum distillation resulted in a pot residue which contained the monomer. Extraction of the residue with hexane
$(3 \times 20 \mathrm{~mL})$ and evaporation of the solvent gave $95 \%$ pure monomer in $50 \%$ yield.

Stearyl $\alpha$-Stearoxymethylacrylate (7d). Stearyl alcohol $(32.54 \mathrm{~g}, 120.3 \mathrm{mmol})$, TEA $(12.17 \mathrm{~g}, 120.3 \mathrm{mmol})$, and dry THF $(60 \mathrm{~mL})$ were placed in a $250 \mathrm{~mL}$ round-bottom flask which was heated to $45^{\circ} \mathrm{C}$. CMAC $(7.6 \mathrm{~g}$, $54.7 \mathrm{mmol}$ ) was added dropwise with rapid stirring. The reaction solution was refluxed for 5 days. $50 \mathrm{~mL}$ THF was added and the mixture was filtered to separate most of the TEAhydrochloride salt. The THF was evaporated and $100 \mathrm{~mL}$ benzene added. The benzene solution was washed 3 times with water $(50 \mathrm{~mL}$ portions). The organic layer was separated, dried with anhydrous sodium sulfate and the solvent removed under reduced pressure. The solid residue was repeatedly washed with methanol to remove unreacted stearyl alcohol, yielding essentially pure monomer as a white solid in $40 \%$ yield; GC analysis was not possible on this monomer but purity was observed to be high by ${ }^{13} \mathrm{C}$ NMR and the fact that polymer was obtained.

2-Phenoxyethyl $\alpha$-(2-Phenoxyethoxy)methylacrylate (7e). 2-Phenoxyethanol (15.3 g, 111 $\mathrm{mmol})$, and TEA $(11.2 \mathrm{~g}, 111 \mathrm{mmol})$, and CMAC (7.0 g, $50.4 \mathrm{mmol})$ were reacted as per 7c. Purification involved final extraction with cyclohexane $(3 \times 20 \mathrm{~mL})$ and evaporation of the solvent to give $94 \%$ pure monomer in $45 \%$ yield.

Pyrrolidinone Monomer (8). ECMA (3.34 g, $22.5 \mathrm{mmol}), 2$-pyrrolidinone $(2.05 \mathrm{~mL}, 26.3$ $\mathrm{mmol})$, and a teflon-coated magnetic stir bar were placed into a $50 \mathrm{~mL}$ round-bottom flask in an ice bath. TEA $(3.3 \mathrm{~mL}, 23.7 \mathrm{mmol})$ was added dropwise to the stirring solution which was then placed in a $70^{\circ} \mathrm{C}$ oil bath. After $12 \mathrm{~h}, 3.5 \mathrm{~mL}$ of $\mathrm{CH}_{2} \mathrm{Cl}_{2}$ was added to reduce viscosity of the salt/product mixture and allow completion of the reaction. Reaction progress was monitored by gas chromatography and was complete in $15 \mathrm{~h} .20 \mathrm{~mL}$ of $\mathrm{CH}_{2} \mathrm{Cl}_{2}$ was added to reduce viscosity and allow washing (twice) with $1 \% \mathrm{HCl}$ solution (20 mL portions). 
The organic phase was separated and the aqueous phase washed again with $20 \mathrm{~mL}$ of isobutyl alcohol. The organic layers were filtered through phase separation filter paper and combined. Solvents were evaporated and residue distilled to give $2.28 \mathrm{~g}$ of $100 \%$ pure ethyl $\alpha$-pyrrolidinylmethylacrylate in $51 \%$ yield.

$N$-Phthalimide Monomer (9). Ethyl $\alpha$ chloromethylacrylate $(0.97 \mathrm{~g}, 6.5 \mathrm{mmol})$, potassium phthalimide $(1.03 \mathrm{~g}, 5.6 \mathrm{mmol})$, and THF were placed in a round-bottom flask and stirred for $14 \mathrm{~h}$ at $70^{\circ} \mathrm{C}$ under positive dry $\mathrm{N}_{2}$ pressure. The reaction progress was monitored by GC. The THF was removed by rotary evaporation and the resulting solid was recrystallized from warm methanol to give $98 \%$ pure monomer in $37 \%$ yield.

\section{Typical Polymerization Conditions}

Polymerization temperatures and initiator concentrations, SEC estimated number average molecular weights, and intrinsic viscosities are listed in Table I. All polymerizations were conducted using neat monomer samples containing $0.1-1 \mathrm{wt} \% \quad 2,2^{\prime}$-azobis(isobutyronitrile) (AIBN) under dry nitrogen gas. Typical polymerization times ranged from $4-48 \mathrm{~h}$ for the $55-60^{\circ} \mathrm{C}$ reactions and 5-7 days for the $23^{\circ} \mathrm{C}$ reactions. Polymers were isolated by precipitating into hexanes except for the $t$-butyl ester-methyl ether polymer (which was precipitated into a 10:1 acetonewater solution from acetone) and the stearyl ester-stearyl ether polymer (precipitated into $1: 1 n$-butanol-ether).

\section{Photopolymerization}

Photoinitiation experiments were performed in a Du Pont 912 Dual Sample DSC with a Du Pont 930 Differential Photocalorimeter Accessory with a 200 watt mercury lamp. Energy intensity at $400 \mathrm{~nm}$ at the sample site was measured at $38 \mathrm{~mW} \mathrm{~cm}^{-2}$ using an International Light Inc. photometer. Total exotherm was taken as the area under the exotherm curve with the baseline extrapolated back from the end of the exotherm to the initial rise from the lamp turning on.

\section{Emulsion Polymerization}

Deionized water $(200 \mathrm{~mL})$, ammonium persulfate $(3 \mathrm{mg})$, sodium thiosulfate $(2.5 \mathrm{mg})$, and sodium lauryl sulfate $(1.0 \mathrm{~g})$ were placed in a $250 \mathrm{~mL}$ Erlenmeyer flask. Dry nitrogen was bubbled through the solution to remove dissolved oxygen. $1.0 \mathrm{~g}$ ethyl $\alpha$-ethoxymethylacrylate was placed in a test tube with a small teflon-coated magnetic stirring bar and $7 \mathrm{~mL}$ of the stock solution added. The test tube was placed into a $35^{\circ} \mathrm{C}$ oil bath with nitrogen bubbling through the solution. The polymerization occurred over a period of two hours during which the temperature of the oil bath reached $65^{\circ} \mathrm{C}$. The polymer was isolated by extraction from the emulsion with $\mathrm{CH}_{2} \mathrm{Cl}_{2}$ due to problems coagulating into $\mathrm{NaCl}$ solution. Evaporation of solvent left $0.02 \mathrm{~g}$ of polymer; $2 \%$ yield.

\section{RESULTS AND DISCUSSION}

\section{Monomer Synthesis}

The ether forming reaction is, in general, very clean with no transesterification or side reactions noted. The first step (or a competitive step) in the reaction is formation of the triethylammonium chloride salt as seen qualitatively by ${ }^{13} \mathrm{C}$ NMR and GC. For some systems, using only a stoichiometric amount of TEA slows the reaction since the TEA is chemically bound as the quaternary salt and cannot activate the alcohol for nucleophilic attack by acting as a general base catalyst. While essentially no reaction occurs in these systems at a $1: 1$ ratio over an extended reaction period, times of $8-24 \mathrm{~h}$ are sufficient with excess TEA.

Monomers obtained were purified by distillation, extraction, or recrystallization. Purity did not seem to be the reason for obtaining low molecular weights since even the most rig- 
Ether Substituted Methacrylates

Table I. Polymerization conditions and polymer properties for alkyl $\alpha$-alkoxymethylacrylates

\begin{tabular}{|c|c|c|c|c|c|c|c|}
\hline \multirow{2}{*}{ Polymer } & \multirow{2}{*}{$\begin{array}{l}\begin{array}{l}\text { AIBN } \\
\text { concn }\end{array} \\
\text { wt } \%\end{array}$} & \multirow{2}{*}{$\frac{\begin{array}{c}\text { Polym. } \\
\text { temp }\end{array}}{{ }^{\circ} \mathrm{C}}$} & \multirow{2}{*}{$\frac{[\eta]}{\mathrm{dL} \mathrm{g}^{-1}}$} & \multicolumn{3}{|c|}{$\begin{array}{l}\text { GPC results } \\
(/ 1000)^{\mathrm{a}}\end{array}$} & \multirow{2}{*}{$\begin{array}{r}T_{\mathrm{g}} \\
{ }^{\circ} \mathrm{C}\end{array}$} \\
\hline & & & & $M_{n}$ & $M_{w}$ & $M_{\mathrm{p}}$ & \\
\hline $\begin{array}{l}\text { Methyl ether } \\
\text { Methyl ester }\end{array}$ & 0.2 & 60 & 0.50 & 89 & 196 & 150 & 96 \\
\hline $\begin{array}{l}\text { Methyl ether } \\
\text { Ethyl ester }\end{array}$ & $\begin{array}{l}0.2 \\
0.4\end{array}$ & 60 & 0.60 & 58 & 181 & 108 & 65 \\
\hline $\begin{array}{l}\text { Benzyl ether } \\
\text { Ethyl ester }\end{array}$ & 1.0 & 55 & 0.24 & 40 & 128 & 56 & 65 \\
\hline $\begin{array}{l}\text { Cyanoethyl ether } \\
\text { Ethyl ester }\end{array}$ & $0: 5$ & 55 & 0.31 & 36 & 88 & 56 & 45 \\
\hline $\begin{array}{l}\text { Pyrr. ether } \\
\text { Ethyl ester }\end{array}$ & $\begin{array}{l}1.0 \\
0.1\end{array}$ & 23 & 0.32 & NA & NA & NA & 26 \\
\hline $\begin{array}{l}\text { Morph. ether } \\
\text { Ethyl ester }\end{array}$ & $\begin{array}{l}1.0 \\
0.1\end{array}$ & $\begin{array}{l}23 \\
60\end{array}$ & 0.45 & NA & NA & NA & 34 \\
\hline $\begin{array}{l}\text { Methyl ether } \\
t \text {-Butyl ester }\end{array}$ & $\begin{array}{l}1.0 \\
0.5\end{array}$ & $\begin{array}{l}23 \\
60\end{array}$ & $\begin{array}{l}0.27 \\
0.07\end{array}$ & 81 & 186 & 144 & 85 \\
\hline $\begin{array}{l}\text { Ethyl ether } \\
\text { Ethyl ester }\end{array}$ & 0.2 & 60 & 0.18 & 23 & 45 & 30 & 37 \\
\hline $\begin{array}{l}\text { Ethyl ether } \\
\text { Ethyl ester (TEA) }\end{array}$ & 0.5 & 60 & NA & 22 & 63 & 47 & NA \\
\hline $\begin{array}{l}\text { Ethyl ether } \\
\text { Ethyl ester (Emul.) }\end{array}$ & Redox & $35-65$ & & 129 & 296 & 242 & 22 \\
\hline $\begin{array}{l}\text { Stearyl ether } \\
\text { Stearyl ester }\end{array}$ & 0.2 & 60 & 0.11 & 18 & 27 & 21 & NA \\
\hline $\begin{array}{l}\text { Benzyl ether } \\
\text { Benzyl ester }\end{array}$ & 0.2 & 60 & 0.11 & 17 & 27 & 22 & 62 \\
\hline $\begin{array}{l}\text { 2-Phenoxyethyl ether } \\
\text { 2-Phenoxyethyl Ester }\end{array}$ & 0.2 & 60 & 0.16 & 30 & 60 & 33 & 21 \\
\hline
\end{tabular}

a With reference to polystyrene standards.

orously purified samples (e.g., the ether-ethyl ester compound was $>99 \%$ pure) showed essentially the same behavior as seen for other derivatives. More importantly, similarly prepared and purified ester derivatives were found to polymerize to very high molecular weight. ${ }^{16}$ ${ }^{13} \mathrm{C}$ NMR chemical shifts of selected carbons of the monomers and intermediates described here are summarized in Table II.

\section{Polymerization Results}

1,1-Disubstituted vinyl monomers often display lower polymerization rates and ceiling temperatures than monosubstituted analogs. 
Table II. Selected ${ }^{13} \mathrm{C}$ chemical shifts for monomers in $\mathrm{CDCl}_{3}$

\begin{tabular}{|c|c|c|c|c|c|c|}
\hline & $=\mathrm{CH}_{2}$ & $=\mathrm{C}$ & $\mathrm{C}=\mathrm{O}$ & $\mathrm{CO}_{2} \underline{\mathrm{C}}$ & $\mathrm{CH}_{2} \mathrm{OCH}_{2} \mathrm{C}=$ & $\mathrm{COCH}_{2} \mathrm{C}=$ \\
\hline $3 \mathbf{a}$ & 124.7 & 139.7 & 166.1 & 60.5 & $\left(\mathrm{HOCH}_{2} \mathrm{C}=\right) 61.3$ & NA \\
\hline 3b & 128.1 & 136.9 & 164.7 & 61.0 & $\left(\mathrm{Cl} \underline{-} \mathrm{H}_{2} \mathrm{C}=\right) 42.3$ & NA \\
\hline $3 \mathbf{c}$ & 128.5 & 137.2 & 164.4 & 60.9 & $\left(\mathrm{Br} \underline{-} \mathrm{H}_{2} \mathrm{C}=\right) 29.1$ & NA \\
\hline $\mathbf{4 a}$ & 124.4 & 136.9 & 165.0 & 59.9 & 70.1 & \\
\hline $4 b$ & 125.0 & ca. 137.5 & 165.2 & 60.2 & 67.9 & 72.2 \\
\hline $4 c$ & 125.4 & 136.2 & 164.9 & 60.2 & 68.6 & 64.8 \\
\hline 4d & 125.4 & 137.1 & 165.5 & 60.5 & 68.9 & 68.9 \\
\hline $4 e$ & 124.9 & 136.9 & 165.2 & 60.1 & 68.7 & 67.8 \\
\hline $4 f$ & 125.4 & 136.8 & 165.4 & 60.4 & 68.6 & 67.4 \\
\hline 5 & 122.5 & 138.5 & 163.6 & 79.3 & 69.9 & 57.4 \\
\hline 6 & 136.3 & 140.9 & 166.5 & NA & $\left(\mathrm{Cl}^{\mathrm{C}} \mathrm{H}_{2} \mathrm{C}=\right) 41.4$ & NA \\
\hline $7 \mathbf{a}$ & 125.0 & 136.7 & 165.6 & 51.1 & 70.2 & 57.8 \\
\hline $7 \mathbf{b}$ & 123.8 & 137.2 & 164.8 & 59.6 & 67.9 & 65.4 \\
\hline $7 c$ & 125.7 & 136.9 & 165.0 & 65.8 & 68.0 & 72.2 \\
\hline $7 d$ & 125.2 & 137.6 & 166.0 & 64.7 & 68.8 & 71.1 \\
\hline $7 e$ & 126.0 & 136.5 & 165.2 & 62.7 & 65.3 & 66.8 \\
\hline 8 & 124.6 & 134.3 & 164.5 & 59.6 & $\left(\mathrm{NC} \mathrm{H}_{2} \mathrm{C}=\right) 46.1$ & NA \\
\hline 9 & 125.6 & 134.4 & 165.1 & 60.9 & $\left(\mathrm{~N} \underline{C} \mathrm{H}_{2} \mathrm{C}=\right) 38.1$ & NA \\
\hline
\end{tabular}

In fact, any $\alpha$-alkyl substituent on acrylic monomers larger than methyl effectively inhibits polymerization, ${ }^{21}$ apparently due to ceiling temperatures close to room temperature. ${ }^{22}$ In contrast, the monomers described here containing the oxygen atom $\beta$ to the vinyl group show higher reactivities than analogous alkane containing monomers and even methyl methacrylate. ${ }^{3}$ It has also been shown that $\alpha$-alkoxymethyl substituted acrylic monomers copolymerize more rapidly than methyl methacrylate with styrene, although when the ether alkyl group gets very large (dodecyl ether) ${ }^{3}$ reactivity decreases. Molecular weights, in contrast, are lower than those of methacrylic ester polymers (apparently because of chain transfer to monomer) but higher than polymers from $\alpha$-alkylacrylates. For example, molecular weights of 4200 have been achieved for poly(methyl ethacrylate) ${ }^{22}$ and 37000 for $\alpha$-ethylacrylic acid ${ }^{21}$ compared to 90000 for methyl $\alpha$-methoxymethylacrylate, a substantial increase considering the similar steric size of the ethyl and methoxymethyl groups.

Evidence of chain transfer is seen when comparing rate constants of propagation and termination and number average molecular weights determined by others. ${ }^{3}$ The kinetic chain length (the number of monomer units reacted per initiator fragment) of a thermally initiated free radical polymerization is defined as (eq 1). ${ }^{23}$

$$
v=\frac{k_{\mathrm{p}}[\mathrm{M}]}{2\left(f k_{\mathrm{d}} k_{\mathrm{t}}[\mathrm{I}]\right)^{1 / 2}}
$$

Kinetic chain length in terms of $k_{\mathrm{p}}$ (propagation rate constant), $k_{\mathrm{t}}$ (termination rate constant), $k_{\mathrm{d}}$ (initiator decomposition rate constant), $f$ (initiator efficiency), $[\mathrm{M}]$ (monomer concentration) and [I] (initiator concentration).

Under conditions of identical initiators and initiator/monomer concentrations, the kinetic chain length is proportional to $k_{\mathrm{p}} / k_{\mathrm{t}}{ }^{1 / 2}$. Calculation of kinetic chain lengths for methyl $\alpha$-butoxymethylacrylate $\left(\mathrm{MC}_{4} \mathrm{MA}\right)$ and methyl methacrylate (MMA) under identical polymerization conditions (from ref 3) gives a kinetic chain length that is $13 \%$ higher for MMA. However, the measured degree of polymerization for MMA is 4.7 times higher. Even taking into account the possible differ- 
ences in modes of termination (67 to $80 \%$ disproportionation for MMA, ${ }^{23}$ unknown for $\mathrm{MC}_{4} \mathrm{MA}$ ), chain transfer must be occurring. This chain transfer process appears to be very dependent on the type of functional group at the $\beta$ position. Recent work on $\alpha$-acetoxymethylacrylates has shown that very high molecular weights are obtained despite larger functional groups even for the $t$-butyl $\alpha$ acetoxymethylacrylate monomer; very low molecular weight was obtained for the $t$-butyl $\alpha$-methoxymethyl derivative (5). ${ }^{16}$ Clearly, electronic factors due to the $\beta$-functional group play a key role in enhancing monomer reactivities even to the extent of overcoming steric inhibition in the propagation step and in reducing chain transfer processes in the polymerization.

A referee has suggested that differences in times and temperatures of polymerizations may be causing the large differences in molecular weight. However, all the polymerizations were carried out under similar initiator concentrations and lengths of time, and several were analyzed during polymerization by SEC which indicated that the molecular weight did not vary significantly over the initial $50-60 \%$ of conversion.

Emulsion polymerization of $7 \mathbf{b}$ gave a polymer with a molecular weight 5 times higher (12900 versus 23000) than the polymer from bulk polymerization due to the lower termination rate inherent to the emulsion polymerization technique. This offers a possible route to high molecular weights from these monomers despite the inherent chain transfer problems, although conditions leading to higher yields must be developed.

\section{Ethyl Ester Polymers}

The ethyl ester monomers polymerized to molecular weights of 23 to 90 thousand (Table I). Of the ethyl ester monomers synthesized, the methyl, ethyl, and benzyl ethers polymerized relatively rapidly, giving high conversions in short times as indicated by a subs- tantial viscosity increase of the polymerizing bulk monomer within a few hours after initiation. Glass transition temperatures for these polymers ranged from $37^{\circ} \mathrm{C}$ for the ethyl ether polymer to $65^{\circ} \mathrm{C}$ for the benzyl and methyl ether polymers (see Table I). The $T_{\mathrm{g}}$ of the benzyl ether polymer is approximately $25^{\circ} \mathrm{C}$ lower than a similar phenyl-ether substituted polymer ${ }^{14}$ which possesses one less $\mathrm{CH}_{2}$ unit in the side chain. The $T_{\mathrm{g}}$ of the polymers appears to be affected mainly by the size of the substituent and the length of the side chain as shown by the low values for the polymers with ethoxy spacer linkages between the backbone and the pendent substituent, but molecular weight differences probably also play a latge part in determining $T_{\mathrm{g}}$ since they are all most likely below the molecular weight (approximately 100000 to 200000 for methacrylate polymers $)^{24}$ where physical properties tend to asymptote. The polarity of the substituent and dipolar interactions are relatively ineffective in increasing $T_{\mathrm{g}}$ as shown by the polymer of $\mathbf{4 c}$ which contained the polar nitrile group yet displayed a $T_{\mathrm{g}}$ of only $45^{\circ} \mathrm{C}$.

${ }^{13} \mathrm{C}$ NMR spectra of the ethyl ester polymers confirmed expected structures. A representative spectrum is shown in Figure 3. Peak assignments are as indicated by the included structure. Several of the peaks in the spectrum indicate tacticity information, as is seen even more clearly for the dimethyl derivative discussed below.

\section{t-Butyl Ester Derivative (5)}

The $t$-butyl ester group is well known for acid-catalyzed elimination yielding the carboxylic acid and isobutylene. We have used this reaction to deprotect the polymer of $t$ butyl $\alpha$-hydroxymethylacrylate. ${ }^{15}$ However, this acid catalyzed reaction has been an obstacle to synthesis of the $t$-butyl ester $\alpha$-butyl ester $\alpha$-halomethyl intermediates due to premature deprotection form the acid generated during conversion of the hydroxyl group to primary halide. Conversion of the alcohol to 


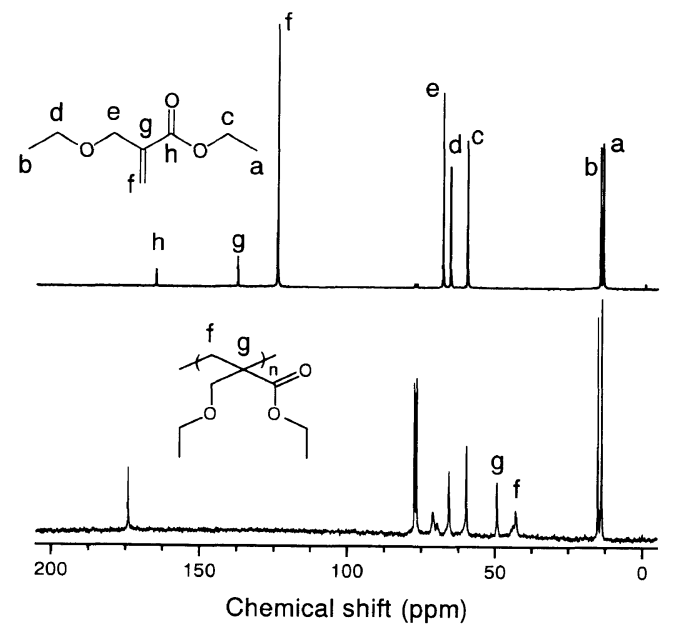

Figure 3. Representative ${ }^{13} \mathrm{C}$ spectra of ethyl $\alpha$-ethoxymethylacrylate monomer (top) and polymer (bottom).

the bromide for the acid-sensitive $t$-butyl ester monomer is possible using $\mathrm{PBr}_{3}$ in ether. ${ }^{7,19}$ Apparently the phosphoric acid derivatives generated using this synthetic scheme do not promote the elimination reaction.

The polymer of the methyl ether of $t$-butyl $\alpha$-hydroxymethylacrylate was synthesized and deprotected using trifluoroacetic acid ${ }^{15}$ (Figure 4) with a catalytic amount of aqueous $\mathrm{HCl}$. Trifluoroacetic acid was evaporated and the polymer precipitated from water into acetone. The protected polymer was soluble in acetone, $\mathrm{CHCl}_{3}$, hexanes, and methanol while the deprotected polymer appeared to be soluble only in water but showed a lower critical solution temperature between 27 and $28^{\circ} \mathrm{C}$ at a concentration of $c a 0.03 \mathrm{~g} \mathrm{~mL} .^{-1}$ The $T_{\mathrm{g}}$ of the protected polymer was $85^{\circ} \mathrm{C}$ due to the effect of the bulky $t$-butyl group next to the polymer backbone. ${ }^{13} \mathrm{C}$ NMR spectra of the monomer, polymer and deprotected polymer are shown in Figure 5. Use of the $t$-butyl ester offers a facile route to ether functionalized acrylic acid monomers, polymers, and copolymers.

\section{2-Hydroxyethyl-Linked Derivatives}

The ether-forming reation of 2-hydroxy-

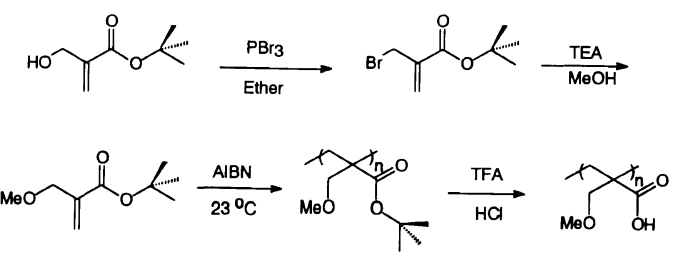

Figure 4. Synthetic scheme for $t$-butyl $\alpha$-methoxymethylacrylate monomer, polymer and deprotected polymer.

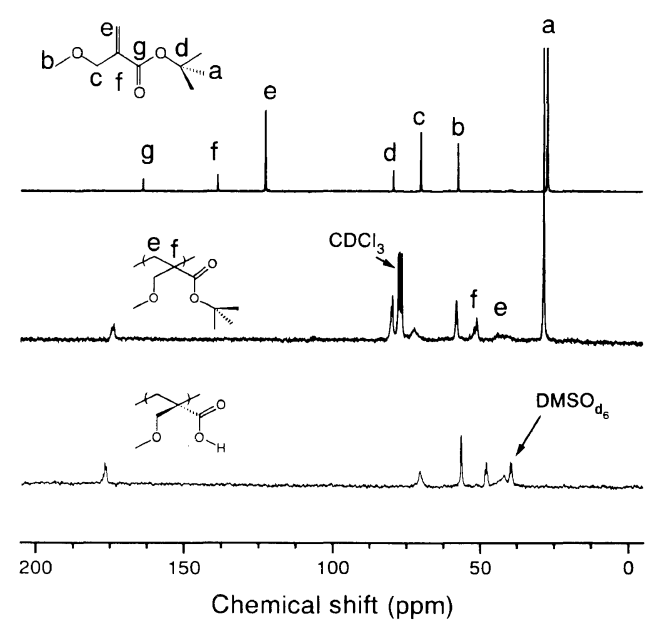

Figure 5. Spectra of $t$-butyl $\alpha$-methoxymethylacrylate monomer (top), polymer (middle) and deprotected polymer (bottom).

ethyl-2-pyrrolidinone with ethyl $\alpha$-chloromethylacrylate produced a monomer which did polymerize under normal bulk polymerization conditions $\left(60^{\circ} \mathrm{C}\right.$ with $\left.\mathrm{AIBN}\right)$ although poorly as shown by its low intrinsic viscosity (Table I). With the low ceiling temperatures of the ethacrylate monomer in mind, polymerizations were attempted at room temperature with a higher concentration of AIBN. This gave a polymer with intrinsic viscosity of 0.32 $\mathrm{d} \mathrm{Lg}^{-1}$ in contrast to $0.1 \mathrm{~d} \mathrm{Lg}^{-1}$ for the high temperature polymerization. This behavior is indicative of a low polymerization ceiling temperature. Ceiling temperatures were estimated for this monomer and the morpholine ether monomer as described in the next section.

The polymer showed unusual solubility properties in that it was soluble in both $\mathrm{H}_{2} \mathrm{O}$ 
and $\mathrm{CHCl}_{3}$, producing clear films from chloroform and cloudy ones from water. The glass transition of the polymer is $26^{\circ} \mathrm{C}$ probably due to plasticization by the bulky substituent.

The $\alpha$-morpholine derivative is very interesting in that it contains a tertiary amine functional group. Tertiary amines are reported to undergo chain transfer with methacrylates. ${ }^{25}$ Despite the $1: 1$ ratio of tertiary amine to polymerizable moiety, this species polymerized to fairly high molecular weight (intrinsic viscosity of $0.45 \mathrm{~d} \mathrm{Lg}^{-1}$ for $23^{\circ} \mathrm{C}$ polymerization). No sign of crosslinking was evident by ${ }^{13} \mathrm{C}$ NMR and the fact that the polymer was soluble in chloroform, THF and toluene. It was partially soluble in water but insoluble in hexane. SEC results were unobtainable due to fact that the polymer crosslinked after sitting exposed to light and oxygen for several weeks; we believe that oxidative coupling at the positions $\alpha$ to the amine groups is responsible, a possibility consistent with uses of related materials as antioxidants. ${ }^{26,27}$ The glass transition temperature of the polymer is $34^{\circ} \mathrm{C}$ probably also due to internal plasticization by the morpholine group. This monomer may have use as an oxygen scavenger in photopolymerization systems where it can be incorporated into the polymer matrix rather than remaining in the matrix as an extractable plasticizer. ${ }^{26}$ Morpholine compounds are also used as corrosion inhibitors, antioxidants, and surface active agents, ${ }^{27}$ suggesting additional uses.

An experiment was devised to test the general susceptibility of the ether monomers to chain transfer by triethylamine, which has a reported $^{25}$ chain transfer constant in MMA polymerizations of $8.3 \times 10^{-4}$. Triethylamine $(0.25 \mathrm{~mL}, 1.8 \mathrm{mmol})$ was added to ethyl $\alpha$ ethoxymethylacrylate $(\mathbf{7 b}, 0.58 \mathrm{~g}, 3.7 \mathrm{mmol})$ along with $0.5 \%$ AIBN. The monomer was polymerized at $60^{\circ} \mathrm{C}$ and isolated to give $74 \%$ conversion. Solidification occurred within $10 \mathrm{~h}$ and SEC results showed essentially the same
$M_{\mathrm{n}}$ as $7 \mathrm{~b}$ polymerized without TEA but a higher $M_{w}$. The polydispersity index wax 2.8 versus 2.0 for neat monomer polymerized under the same conditions, which seems to indicate some chain transfer but nowhere near that expected based on MMA results. In comparison, MMA polymerized at this concentration in tripropylamine (chain transfer constant of $1.46 \times 10^{-3}$ ) at $60^{\circ} \mathrm{C}$ with 0.01 wt $\%$ AlBN would suffer a factor of 9 drop in molecular weight. ${ }^{28}$ One explanation for the higher weight average molecular weights may be branching or multiple chain termination to triethylamine radicals although no sign of triethylamine fragments was seen by ${ }^{13} \mathrm{C}$ NMR.

\section{Ceiling Temperature Estimations}

Polymerization temperature had a very significant affect on the molecular weight of the polymers as shown by intrinsic viscosities. Polymerization of the morpholine derivative at $60^{\circ} \mathrm{C}$ gave a polymer with an intrinsic viscosity of approximately $0.1 \mathrm{~d} \mathrm{Lg}^{-1}$ while polymerization at $23^{\circ} \mathrm{C}$ gave a value of $0.45 \mathrm{~d} \mathrm{Lg}^{-1}$. This suggests a low ceiling temperature $\left(T_{\mathrm{c}}\right)$.

Low ceiling temperatures have been proposed for monomers containing large substituents close to the vinyl group such as ethyl and methyl $\alpha$-phenoxymethylacrylates. ${ }^{14}$ Three of the monomers described here (4d, 4e, and 5) appear to have low ceiling temperatures as indicated by the effect of temperature on intrinsic viscosity for bulk polymerization. The ceiling temperatures were investigated using photoinitiated polymerization over a range of temperatures. As polymerization temperature approaches the ceiling temperature, the total exotherm of the polymerization and the maximum rate of reaction drop due to the competing depropagation reaction. The ceiling temperature can be approximated by plotting total exotherm or maximum reaction rate versus temprature and extrapolating to zero exotherm or zero reaction rate (Figure 6). The plots show that the morpholine substituted 


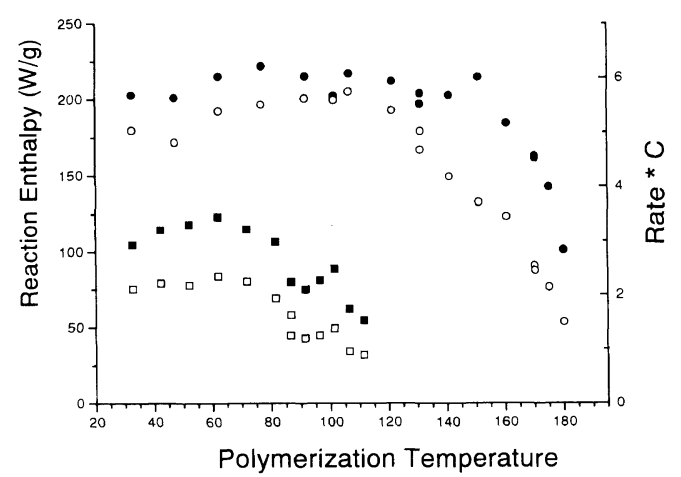

Figure 6. Plots of polymerization enthalpy (solid) and maximum rate (open) versus polymerization temperature for $\mathbf{4 d}$ (squares) and $\mathbf{4 e}$ (circles).

monomer has a ceiling temperature of $\sim 120^{\circ} \mathrm{C}$ while the pyrrolidinone monomer showed a ceiling temperature of approximately $180^{\circ} \mathrm{C}$, both lower than methyl methacrylate $\left(T_{\mathrm{c}}=\right.$ $220^{\circ} \mathrm{C}$ ). The methyl ether $/ t$-butyl ester monomer also showed the effects of temperature on molecular weight, giving an intrinsic viscosity of $0.07 \mathrm{dL} \mathrm{g}^{-1}$ when polymerized at $60^{\circ} \mathrm{C}$ and $0.27 \mathrm{dL} \mathrm{g}^{-1}$ when polymerized at $23^{\circ} \mathrm{C}$. Due to volatility of the monomer, the ceiling temperature was not determined by the photoinitiation method described.

\section{Symmetrically-Substituted Monomers}

Monomers 7a-7e were synthesized to study the effect of incorporation of two bulky pendant groups per monomer molecule on polymer properties. Synthesis of these monomers from the reactive intermediate CMAC (6) was facile, involving reaction of $2.2 \mathrm{~mol}$ of the required hydroxy-terminated species with 1 mol of CMAC using excess TEA as catalyst and base. Monomers were obtained with pendant groups attached via both ester and ether linkages (Figure 7). The effect of larger substituents is demonstrated by the lower molecular weight for the ethyl ether of ethyl $\alpha$-hydroxymethylacrylate compared to the methyl ether (4a and $\mathbf{7 b}$, respectively) despite the lower initiator concentration used for $\mathbf{7 b}$. As shown in Table $\mathrm{I}$, the $T_{\mathrm{g}}$ of the polymer

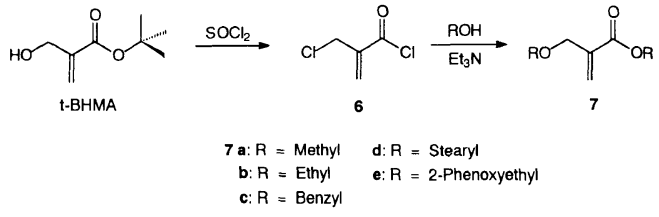

Figure 7. Synthetic scheme for symmetrical ether monomers.

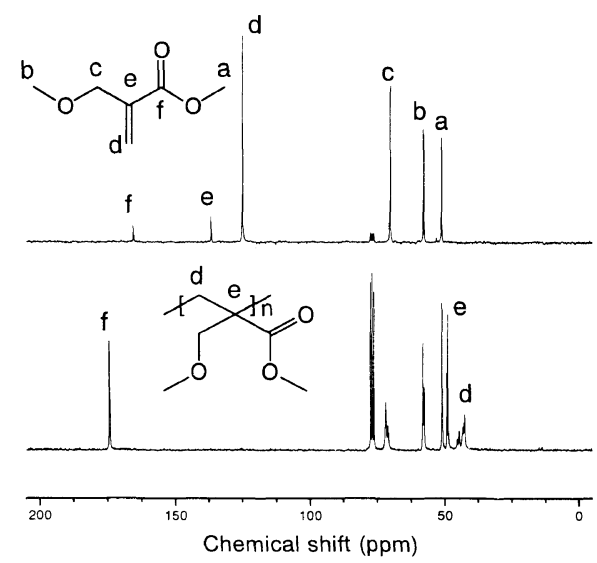

Figure 8. ${ }^{13} \mathrm{C}$ NMR spectra of methyl $\alpha$-methoxymethylacrylate monomer (top) and polymer (bottom).

obtained from the bis-benzyl species (7c) is $65^{\circ} \mathrm{C}$, while that of the bis-(2-phenoxyethyl) species (7e) is $21^{\circ} \mathrm{C}$. This can be attributed to the ethylene spacer in the latter, which reduces interaction between the bulky pendant phenyl ring and the polymer backbone. The bis-stearyl monomer (7d) showed no $T_{\mathrm{g}}$ although it did show side chain melting at $49^{\circ} \mathrm{C}$.

${ }^{13} \mathrm{C}$ NMR peak shapes are very well-defined for the dimethyl derivative (7a) (Figures 8 and 9) probably due to more rapid motion of the polymer backbone in solution as a result of the smaller substituents. The separate groups of peaks for some carbons indicate tacticity of the polymer backbone, but no detailed assignments have been made.

\section{Non-Polymerizable Nitrogen-Linked Deriva- tives}

Based on the results of the ether linked monomers several nitrogen-linked monomers 


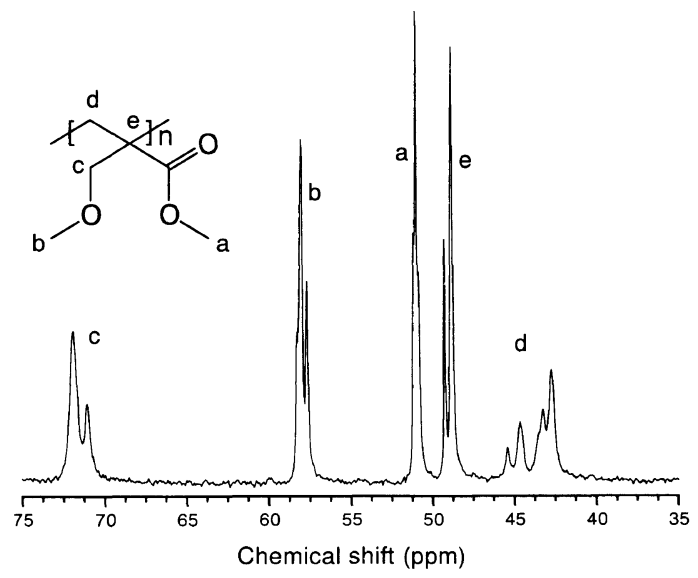

Figure 9. Expansion of Figure 8.

were synthesized $(\mathbf{8}, \mathbf{9})$. These monomers did not polymerize, most likely due to steric hindrance of the propagation or initiation step. No signs of free-radical addition were seen for these monomers even after several days of AIBN initiation at $60^{\circ} \mathrm{C}$. Similar steric effects have been seen for methyl (2-hydroxy-2methyl)methacrylate produced via the same synthetic scheme as used for 3a except with acetaldehyde. Apparently the branch point of the bulky substituent is too close to the double bond to allow proper orientation of the incoming radical for bond formation.

\section{CONCLUSIONS}

We have demonstrated the ease of synthesis of a variety of $\alpha$-ether substituted acrylic monomers and the ability to achieve homopolymers of moderate molecular weight despite the presence of large substituents. These monomers polymerize unexpectedly well in comparison to $\alpha$-( $n$-alkyl)-substituted acrylic monomers indicating that the ether oxygen may be helping to overcome the combined electronic and steric effects of the alkyl sidechains. The alkyloxymethyl linkage thus makes a wide range of functionalized monomers and their polymers available with the caveat that branching at the atom $\alpha$ to the heteroatom completely inhibits polymerization. Recent work with $\alpha$-acetoxymethyl monomers indicates that reactivity is also dependent on the electronic character of the functional group; solubility and solution properties of these polymers may have value in tailoring desired end-use properties via functionalization or copolymerization.

Finally, the $t$-butyl ester derivatives make available a wide range of functionalized acrylic acid monomers and polymers by removal of the $t$-butyl group before or after polymerization.

Acknowledgements. We gratefully acknowledge the National Science Foundation (DMR9111903) and NASA for partial support of this work and the Department of Defense for an instrumentation grant through the Office of Naval Research for our Bruker MSL 200.

\section{REFERENCES AND NOTES}

1. K. Chikanishi and T. Tsuruta, Makromol. Chem., 81, 198 (1965).

2. M. C. Monreal-Fernández, R. Cuervo, and E. L. Madruga, J. Polym. Sci, A, Polym. Chem., 30, 2313 (1992).

3. B. Yamada, M. Satake, and T. Otsu, Makromol. Chem., 192, 2713 (1991).

4. S. F. Reed and M. G. Baldwin, J. Polym. Sci., A, Polym. Chem., 1, 1919 (1964).

5. L. J. Mathias, S. H. Kusefoglu, and A. O. Kress, Macromolecules, 20, 2326 (1987).

6. A. F. Ferris, J. Org. Chem., 20, 780 (1955).

7. J. Villieras and M. Rambaud, Synthesis, 924 (1982).

8. H. M. R. Hoffman and J. Rabe, Angew. Chem. Int. Ed. Engl., 22, 795 (1983).

9. S. F. Reed and M. G. Baldwin, J. Polym. Sci., A, Polym. Chem., 2, 1355 (1964).

10. S. C. Warren and L. J. Mathias, J. Polym. Sci., Polym. Chem. Ed., 28, 1637 (1990).

11. R. D. Thompson, W. L. Jarrett, and L. J. Mathias, Macromolecules, 25, 6455 (1992).

12. C. P. Jariwala, P. G. Sundell, C. E. Hoyle, and L. J. Mathias, Macromolecules, 24, 6532 (1991).

13. L. J. Mathias, S. Lee, J. R. Wright, and S. C. Warren, J. Appl. Polym. Sci., 42, 55 (1991).

14. R. W. Lenz, K. Saunders, T. Balakrishnan, and K. Hatada, Macromolecules, 12, 392 (1979).

15. L. J. Mathias, R. M. Warren, and S. Huang, 
Macromolecules, 24, 2036 (1991).

16. D. Avci, S. H. Kūsefoğlu, R. D. Thompson, and L. J. Mathias, J. Polym. Sci., A, Polym. Chem., 32, 2937 (1994).

17. The monomer was dissolved in methanol and small amounts of water added until crystallization started.

18. The transesterification product was identified by the presence of two ethyl ester peaks and a new peak for the carbon next to the phthalimide nitrogen. The ratio of ethyl ester to phthalimide ester was calculated from peak heights and yield calculated accordingly.

19. P. Knochel, T. Chou, C. Jubert, and D. Rajagopal, J. Org. Chem., 58, 588 (1993).

20. Due to the low boiling point of the monomer we found it necessary to distill this monomer either by carefully controlling the pressure on a good vacuum pump or by using a poor one. Alternatively, a chilled condenser with chilled receiving flask may be used. Care must also be taken that excess thionyl chloride is not condensed with the monomer.

21. J. Cheng, B. Yamada, and T. Otsu, J. Polym. Sci., Polym. Chem. Ed., 29, 1837 (1991).
22. J. Penelle, J. Collot, and G. Rufflard, J. Polym. Sci., Polym. Chem. Ed., 31, 2407 (1993).

23. G. G. Odian, "Principles of Polymerization," 2nd ed, 1970, John Wiley and Sons, New York, N.Y., 1970, pp 223-225.

24. B. B. Kine and R. W. Novak, in "Encyclopedia of Polymer Science and Engineering," Vol. 1, J. I. Kroschwitz, Ed., John Wiley \& Sons, New York, N.Y., 1986, p 260.

25. C. H. Bamford and E. F. T. White, Trans. Faraday Soc., 52, 716 (1955).

26. C. E. Hoyle and K. Kim, J. Radiat. Curing, 12, 9 (1985).

27. "The Merck Index," 11 th ed, S. Budavari, Ed., Merck and Company, Inc., Rahway, N.J., 1989.

28. Calculated by extrapolation of (degree of polymerization) $)^{-1}$ versus (chain transfer agent concentration)/(monomer concentration) to the proper concentration using results from $\mathrm{T}$. Huff and $\mathrm{E}$. Perry, J. Polym. Sci., Polym. Chem. Ed., 1, 1553 (1963). 